\title{
The morality of abortion and the deprivation of futures
}

Mark T Brown University of Wisconsin Colleges, Wausau, Wisconsin, USA

\begin{abstract}
In an influential essay entitled Why abortion is wrong, Donald Marquis argues that killing actual persons is wrong because it unjustly deprives victims of their future; that the fetus has a future similar in morally relevant respects to the future lost by competent adult homicide victims, and that, as consequence, abortion is justifiable only in the same circumstances in which killing competent adult human beings is justifiable. ${ }^{1}$ The metaphysical claim implicit in the first premise, that actual persons have a future of value, is ambiguous. The Future Like Ours argument (FLO) would be valid if "future of value" were used consistently to mean either "potential future of value" or "self-represented future of value", and FLO would be sound if one or the other interpretation supported both the moral claim and the metaphysical claim, but if, as I argue, any interpretation which makes the argument valid renders it unsound, then FLO must be rejected. Its apparent strength derives from equivocation on the concept of "a future of value".

(Fournal of Medical Ethics 2000;26:103-107)
\end{abstract}

Keywords: Abortion; Future Like Ours; Donald Marquis; potentiality; pro-choice

In an influential essay entitled Why abortion is wrong, Donald Marquis presents an argument which purports to derive the immorality of abortion from a deceptively simple but intuitively compelling claim: it is presumptively wrong to kill us, competent adult human beings, because doing so destroys our most valuable possession, a future of value. ${ }^{1}$ Marquis claims that killing actual persons is wrong because it unjustly deprives the victim of his or her future; that the fetus has a future similar in morally relevant respects to the future lost by a competent adult homicide victim, and that, as consequence, abortion is justifiable only in the same special and extreme circumstances in which killing competent adult human beings is justifiable. Marquis presents the gist of the Future Like Ours (FLO) argument in this way: "...we can start from the following unproblematic assumption: it is wrong to kill us. . . when I am killed I am deprived of all of the value of my future. Inflicting this loss on me is ultimately what makes killing me wrong. The future of a standard fetus includes a set of experiences, projects, activities and such which are identical with the futures of adult human beings and the futures of young children. Since the reason that is sufficient to explain why it is wrong to kill human beings after the time of birth is a reason that also applies to fetuses, it follows that abortion is prima facie seriously wrong."2

The Future Like Ours argument has been criticised on the grounds that it ignores the point of view of the pregnant woman; that it is incompatible with contraception and abstinence; and that it understates the explanatory resources of the competing personhood theory while overstating its own explanatory power. ${ }^{3}$ These objections make a powerful cumulative case that something is amiss in FLO, but none come to grips with the metaphysical thesis at the heart of the argument: the claim that actual persons possess a future of value. What exactly does it mean to have a future of value?

The expression is ambiguous. It could mean that actual persons have a potential future of value in the sense that given favourable conditions they are likely to have a worthwhile life; or it could mean that actual persons have a self-represented future of value in the sense that they can construct mental representations of valuable futures. The FLO argument turns upon this ambiguity. The expression occurs twice in the argument, first in the claim that homicide is presumptively wrong because it deprives its victim of a future of value, and second in the claim that both actual persons and fetuses have a future of value. The Future Like Ours argument would be valid if "future of value" were used consistently to mean either "potential future of value" or "self-represented future of value", and FLO would be sound if one or the other interpretation supported both the moral claim and the metaphysical claim, but if any interpretation which makes the argument valid 
renders it unsound, then FLO must be rejected. I first argue that the potential future of value interpretation is unsound because it is not presumptively seriously wrong to deprive someone of a potential future of value. I then argue that the self-represented future of value interpretation is unsound because the fetus does not represent its future. The essay concludes with an analysis of the intuitive appeal of the Future Like Ours argument.

\section{I}

The Future Like Ours argument might be salvaged if homicide were presumptively wrong because it deprives a human being of a potential future of value, whether or not that human being ever imagined his or her future. In this case, the expression "a future of value" could be used consistently throughout the argument: killing persons is presumptively wrong because it deprives them of their potential future of value; a fetus has a potential future of value; thus killing a fetus is presumptively wrong. The second premise is plausible. In most cases the course of a pregnancy can be foreseen with enough confidence to predict that the fetus will be born as an infant who has the capacity to enjoy a life qualitatively similar to the lives of actual persons.

The first premise is implausible, in part because a potential future of value interpretation implies welfare rights which most people would reject in other spheres of life. If deprivation of potential futures of value is presumptively a form of culpable homicide, then culpable homicide is committed whenever a person is denied access to what he or she needs to live. A homeless man who dies of exposure, an elderly woman whose unheated apartment precipitates a fatal case of pneumonia, an injured child who dies for want of a suitable blood transfusion would all be homicide victims. Each case is tragic in its own way, but it is far from clear that these persons' rights have been violated. Persons can die in ways which do not violate their rights. ${ }^{4}$ This is not to say that no harm is done when a potential future of value is foreclosed. On the contrary, to prevent a person from acting upon a highly reliable anticipated future imposes upon them significant opportunity costs, but it does not necessarily treat him or her unjustly. Only if the person had a right to the favourable circumstances which make possible a potential future of value would depriving him or her of that future be presumptively wrong.

For example, the future quality of life of many actual persons depends critically upon whether they receive prompt and effective medical treatment. Many persons with end stage renal disease could expect bright futures if they were to receive a kidney transplant, but neither medical need nor therapeutic benefit entitles these persons to medical services. Patients have a right to life-enhancing medical interventions because they subscribe to a health care plan which covers the procedure or because they are citizens of a country which maintains a functioning system of universal health care or for some other reason, but they do not have a right to medical services, or to any other external good, simply because they would have a better future if someone were to provide for their needs.

The potential future of value of the fetus is no less dependent upon favourable external circumstances. Since the fetus will become a person who has the capacity to enjoy its life and derive meaning from it only if it has access to the reproductive system of a woman, abortion would be presumptively wrong only if women had no presumptive right to control access to their reproductive systems. The fetus certainly needs its uterine environment if it is to realise its potential, but persons do not in general have a right to satisfy their needs at the expense of the autonomy, bodily integrity and wellbeing of another person. If I need a bone marrow transplant in order to realise my potential future of value, I do not thereby gain a right to your bone marrow, even if you are my mother. Perhaps pregnancy creates more stringent duties than motherhood, but if so, an argument is needed to establish this claim, an argument notably absent from Marquis's presentation of the Future Like Ours argument.

A defender of FLO might object at this point that abortion kills the fetus and that killing a person does violate his or her rights in all but the most extreme circumstances, even if depriving him or her of life-sustaining services need not, but this is not a distinction that can be drawn within a potential future of value interpretation of FLO. Someone who has been killed and someone who has been denied access to life support have been deprived equally of their potential futures. The potential future of value interpretation fails because the moral premise if true implausibly entitles persons to welfare rights to valuable futures in addition to liberty rights not be killed. A self-represented future of value interpretation is needed to distinguish between the right not be killed and the right to valuable futures.

\section{II}

The Future Like Ours argument would be valid if the expression "a future of value" consistently meant "a self-represented future of value". Substituting in, the argument would look like this: killing persons is presumptively wrong because it 
deprives them of their self-represented future; fetuses have self-represented futures; thus, killing fetuses is presumptively wrong. The first premise is plausible. At any moment a person can project a representation of a self which extends over time, a self understood from the perspective of the present, reconstructed from present remnants of the past and projected from the present into many possible futures. Persons care about their selfrepresented futures and their memories, their self-represented past, because this self-conception defines who they are and confers meaning and significance upon what they think and do. In contrast with potential futures, self-represented futures do not depend upon outside agencies for their realisation. The value of a self-represented future resides within the person herself, as a feature of a richly complex mental life. Killing a person deprives her of this future: her hopes and dreams are dashed, her goals unfulfilled, her sins unforgiven, longed for reunions and reconciliations never occur. All of this happens in the present, to a person able to unite in a moment of self-consciousness a personal past, present and future. One reason why killing persons violates their rights, but depriving them of life support need not, is that killing persons deprives them of a future and a past which is rightfully their own because it is something they themselves have created.

Even if killing a person is presumptively wrong because it deprives its victim of his selfrepresented future, this cannot be a reason why it is wrong to kill a fetus because the fetus does not construct mental representations of its future. The neurological and embryological evidence of this issue is clear. ${ }^{5}$ Higher order cognitive functioning of the type implicated in planning and memory is dependent upon massive cortical/sub-cortical connectivity. Sub-cortical thalamic fibres first begin to form synapses with cortical neurons at about twenty-five weeks' gestation and only at some point well after birth does connectivity reach a critical threshold sufficient for self-awareness. A third trimester fetus may be sentient but there is no medical reason to think it is capable of self-consciousness.

The Future Like Ours argument rests upon two substantive claims: (1) killing persons is presumptively wrong because it deprives them of a future of value; and, (2) fetuses have futures of value. The plausibility of the first claim depends upon the intuition that persons suffer significant harm when prevented from experiencing their selfrepresented future, but since the fetus does not represent its future it cannot be harmed in this way. The plausibility of the second claim depends upon the proposition that both the fetus and actual persons have a potential future of value, but unless one has a right to the conditions under which this potential can be realised, neither homicide nor abortion are presumptively wrong for this reason. The self-represented future of value interpretation underwrites the moral claim about the wrongness of homicide but militates against the metaphysical claim that persons and fetuses are relevantly similar; the potential future of value interpretation uncovers a genuine commonality between persons and fetuses but not one which can support the moral claim that abortion is presumptively seriously wrong. We may conclude that the Future Like Ours argument retains its force only if one equivocates on the concept of a future of value.

\section{III}

How, then, can the enormous intuitive appeal of the Future Like Ours argument be explained? The answer, I think, lies in the subtle and pervasive influence self-representation exerts upon our experience of time. The intentions, memories, hopes, dreams and plans which define us as persons elicit in us powerful intuitions of temporal extension, for ourselves and on behalf of others. Just as the past can come alive in memory, a longawaited future can feel more real than the present. Everyone has had the experience of seeing a longed for future evaporate as events unfold in unexpected and unwelcome ways. When this happens, the sense of loss is palpable, even though nothing physical has been taken away. Nowhere is the reality of a self-represented future more evident than in the attitudes of the dying and bereaved. AIDS victims understand how a foreseen death can alter the experience of time; grieving parents dwell upon how empty their own experience of the passage of time has become. In each case, the past and the future become humanly accessible through mental representations, all of which are expressions of the current mental state of a self-conscious person.

The Futures Like Ours argument is beguiling because in ordinary circumstances potential futures of value are linked to represented futures of value. Indeed, this linkage is the point of contingency planning. As agents, persons act upon the value they assign to representations of their own future precisely because they believe that given favourable circumstances their imagined scenarios will correspond to valuable states of affairs. This linkage between represented futures and potential futures is deeply ingrained in practical reasoning. Any form of delayed gratification or other sacrifice of current interests presupposes a 
representation of a future valued more highly than the present. Savings schedules, life insurance and long term investments make sense only against the backdrop of a perceived future of value; frustrated and impoverished graduate students must remind themselves of the rewards of perseverance; and perhaps most starkly, cancer patients undergo burdensome therapies in the hope that doing so will prolong their futures. Other cancer patients refuse medical intervention in order to have a future perceived as more valuable because free from the toxic effects of chemotherapy. In these and countless other cases, patients consent or withhold consent to medical treatment based upon a judgment of the relative value of alternative futures. All of this is an intelligible and perfectly reasonable response to represented futures believed to be potential futures.

\section{Parenting}

Represented futures and potential futures are conjoined no less when one imagines the future of someone else. When a person enters into relationships she may empathise with and act on behalf of others in the expectation that some of her mental representations of their future will be realised. Parenting is a sphere of life dominated by thoughts of the future on behalf of others. Parents routinely, sometimes obsessively, contemplate the future of their children, hoping that some scenarios will come true and fearing the realisation of others. Why else subject our children to the discipline of learning to read and playing the violin or to the pains of orthodontia? Why else lose sleep over the perils of bicycles, motorcycles and rollerblades? Parents become obsessive about safety because they believe that nothing would be more difficult to bear than the death of their child. The natural, almost inevitable, thought of grieving parents is that the future of their child has been snatched away, that their child has lost a future of falling in love, of worldly success, of raising children of her own and a thousand other worthwhile experiences.

For many women, the thought of the lost future of a fetus aborted in their youth haunts them for a lifetime. These women may replay in their minds first words not spoken and birthdays never celebrated with the same vivacity with which they regret missed opportunities in their own lives and in the lives of their children. These women grieve for their lost child because they have solidly paired a mental representation of a future life as child for their aborted fetus with the potential future of the fetus as it was at the time of the abortion. These attitudes are understandable, but should not impose limits upon the reproductive freedom of other women. One can sympathise with the griefstricken without accepting their beliefs as philosophically perspicuous constraints upon the resolution of problems in medical ethics. Dying people, for example, may exercise their liberty interest in controlling the terms of their own death by creating the illusion of normalcy; Jehovah's Witnesses may give expression to their religious convictions by refusing blood transfusions, but in neither case do the beliefs of these persons need to be taken as true to be taken seriously.

Similarly, one can understand the natural propensity to attribute retrospectively to the fetus the status of a person because in many spheres of life, including parenting, it is entirely reasonable to think and act as if a predictable outcome were actual. In other spheres of life, the connection between represented futures and potential futures is best severed. When drawn into a fictional story for example, or engaged in fanciful daydreams or when under the sway of irrational fears, the proper response is to recognise that one's thoughts fail to correspond to reality. If the fetus is not selfconscious, as the embryological evidence indicates, feelings of regret (and moral outrage) on its behalf are unfounded in the same way feelings of regret and moral outrage on behalf of a fictional character are unfounded. In neither case, is there an appropriate extramental subject of experience upon which to direct our attitudes. One may imagine a future for a fetus in which he or she had his or her own (unfulfilled) hopes and dreams, but one should not fall into the trap of thinking that the fetus as it was at the time of an abortion had a self-represented future to lose. One may mourn the absence of the child the fetus would have become, but in doing so one is coming to terms with a painful mental representation in one's own mental life, not acting on behalf of a person who had a future of his or her own.

\section{Aborted fetuses}

What, then, of the millions of aborted fetuses? Have they been deprived of their future? We may represent a future for them if we choose, but, it is we, self-conscious persons, who make this future. We can also project ourselves into a past of which we have no memory, into early childhood, infancy and in utero. We can represent our self as the human being who is continuous with the infant in the baby pictures and with the fetus in the ultrasound. If we represent the past in this way, we will alter our experience of time and in so doing elicit powerful intuitions of temporal extension and empathetic identification. We can, if we wish, represent to ourselves a future for a fetus, but this is not something the fetus can do. A self- 
represented future is a terrible thing to lose but this is not a misfortune which can befall a fetus. And a potential future is not a benefit to which the fetus has a right. Either way, FLO fails.

Mark T Brown, PhD, is Professor of Philosophy, Department of Philosophy, University of Wisconsin Colleges, Wausau, Wisconsin, USA.

\section{References and notes}

1 Marquis D. Why abortion is immoral. fournal of Philosophy 1989, 86-4: 183-202.
2 See reference 1: 189, 190, 202

3 Cudd A. Sensationalized philosophy: a reply to Marquis's Why abortion is immoral. The fournal of Philosophy 1990;87,5: 262-4. Norcross A. Killing, abortion, and contraception. The fournal of Philosophy 1990;87,5:268-77. Paske G. Abortion and the neo-natal right to life: a critique of Marquis's futurist argument. In Pojman L, Beckwith F, eds. The abortion controversy. Boston: Jones and Bartlett, 1994: 343-53. Similar criticisms Ber journal.

4 Here I draw upon Thomson JJ. A defense of abortion. Philosophy and Public Affairs 1971;1,1:47-56, and the enormous literature this essay has elicited over the years.

5 Flower M. Neuromaturation of the human fetus. Fournal of Medicine and Philosophy 1985;10:237-51. Grobstein C. Science and the unborn. New York: Basic Books, 1988: 55, 130.

\section{News and notes \\ Fifth World Congress of Bioethics}

The International Association of Bioethics has announced that the Fifth World Congress of Bioethics will take place at Imperial College, London from 21-24 September 2000

Associated organisations are: The British Association for the Advancement of Science; the British Medica Association; the European Association of Centres of Medical Ethics; the Institute of Medical Ethics; the

Millenial Festival of Medicine; the Nuffield Council on

Bioethics; the Royal College of Nursing; the Roya
College of Psychiatrists, Philosophy Special Interest Group; the Society for Applied Philosophy; the UK Forum for Healthcare Ethics and Law, and the World Health Organisation.

For further information (and to obtain a preliminary programme, in September/October 1999) please contact: Sara Hassen, 5th World Congress of Bioethics, 1 Riverside, St Anne's Road, Bristol, BS4 4ED or email: enquiries@inanyevent-uk.com or use the Congress Website at http://www.uclan.ac.uk/facs/ethics/fifthcon.htm 